\title{
15
}

\section{Economic growth and environmental pollution: a panel data analysis}

\section{Bao Qun and Shuijun Peng}

The relationship between economic growth and environmental quality has been debated widely for a long period; controversy goes back to the debates about the limits to growth at the end of the 1960s. At one extreme, environmentalists and the economists of the Club of Rome (Meadows et al. 1972) argued that the finiteness of environmental resources would prevent economic growth from continuing forever and argued for a steady-state economy with a zero growth rate to avoid dramatic ecological scenarios in the future. At the other extreme, some economists claimed that technological progress and the substitutability of natural with man-made capital would reduce dependence on natural resources and allow an everlasting growth path. As Beckerman (1992) concluded, 'there is clear evidence that, although economic growth usually leads to environmental degradation in the early stages of the process, in the end the best-and probably the only - way to attain a decent environment in most countries is to become rich.' Bhagawati (1993) wrote, 'economic growth may be a precondition for environmental improvement.' So, according to Panayotou (1993), 'growth could be a powerful way for improving environmental quality in developing countries'.

These theoretical debates induced a number of researchers to examine the systematic relationship between income change and the environment in the past decade. Substantial empirical evidence suggested that the relationships between many forms of pollution and national income followed an inverted-U curve relationship: environmental degradation gets worse in the early stages of growth, but eventually reaches a peak and starts declining as income exceeds a certain threshold level. This inverted-U shape has been defined as the Environmental Kuznets Curve (EKC) after the work of Simon Kuznets (1955), who first observed 
a similar relationship between inequality and economic development. ${ }^{1}$ The logic of EKC relation is intuitively appealing. In the first stage of industrialisation, pollution grows rapidly because high priority is given to increasing material output, and people are more interested in jobs and income than clean air and water (Dasgupta et al. 2002). The rapid growth inevitably results in greater use of natural resources and emission of pollutants, which in turn put more pressure on the environment. People are too poor to pay for pollution abatement and/or disregard environmental consequences of growth. In later stages of industrialisation, as incomes rise, people value the environment more, regulatory institutions become more effective and pollution levels decline. Thus, the EKC hypothesis posits a well-defined relationship between the level of economic activity and environmental pressure (defined as including the level of concentration of pollution or flow of emissions and the depletion of resources).

Following Grossman and Krueger's (1991) groundbreaking study of the potential impact of the North American Free Trade Agreement (NAFTA) on environmental quality through three different channels (that is, scale effects, composition effects and technological effects), an extensive literature has developed reporting EKC estimates and discussing their implications. Earlier papers by Shafik and Bandyopadhyay (1992), Panayotou (1993), Selden and Song (1994) and Grossman and Krueger (1995) presented initial evidence that some pollutants followed an EKC pattern. These findings then led to a naive idea that economic growth is, by nature, the remedy to environmental problems. However, recent researchers have focused on the effects of different pollutant indicators on environmental degradation, the use of a wider range of explanatory variables than income alone and the estimation of different models (see survey in Stern 1998; Ekins 2000; de Bruyn 2000; Panayotou 2000; and Dinda 2004). Within this literature, the EKC results are not generally reproduced.

One important critique of the existing empirical EKC studies is that they are based on a single polynomial equation model in which there is no feedback effect from the environment to economic growth and therefore environmental damage is invariably viewed only as the outcome of economic growth. ${ }^{2}$ Among all of the empirical EKC literature, the effect of economic growth on environmental quality is estimated directly. However, it is well known that, in addition to the effect of economic growth on environmental quality, environmental degradation might impact directly or indirectly on economic growth through multiple channels. First, environmental degradation might act as a negative externality, directly reducing production through the restraints of limited natural resource inputs and the productivity of man-made capital and workers (Barbier 1994; Lopez 1994; Smulder 
1999; de Bruyn 2000). Examples are the loss of working days due to health problems, the corrosion of industrial equipment due to polluted air or water, and product voided because of being polluted. Second, since permitting greater levels of emissions might increase the availability of human and other capital for production, when firms abate pollution emissions, their production costs are raised and outputs are reduced. Generally, economic growth and environmental quality are determined jointly (Perrings 1987). Therefore, it is inappropriate to estimate a single equation model assuming unidirectional causality from economic development to environmental quality change. As Stern (1998) concluded, '[E]stimating single equation relationship by ordinary least squares where simultaneity exists produces biased and inconsistent estimates'. Hence, a simultaneous equations model might be more appropriate for understanding the environment-income relationship.

As de Bruyn (2000) pointed out, however, there have been few empirical studies that estimated the simultaneous relationship between income change and environmental quality. This has been due mainly to the difficulty of model specification and a lack of available environmental data. The first purpose of this chapter is to formulate a simultaneous equations model between per capita income and pollution emission and then to estimate the EKC in China. Based on theoretical implication, a simultaneous two-equation model is constructed. The first (pollution) equation is a polynomial equation used commonly in the EKC empirical literature. The second (income) equation manipulates the pollutant emission as an input in an extended Cobb-Douglas production function. After the simultaneous model is constructed, the second purpose of this study is to investigate the contribution of pollution to production activities and, consequently, to economic growth. In recently developed endogenous growth models, factors such as fertility choice, physical and human capital accumulation, research and development, and pollution have been proposed as the means of explaining output growth. While pollution has been considered important theoretically among these factors (the role of inputs, the adverse impacts on labour, man-made inputs and production) no studies have yet examined empirically the effects of pollution on production in China. The third purpose of our chapter is to investigate pollution control variables and use improved data for testing the EKC hypothesis in China. Recently, abundant provincial macrodata have become available in the Chinese Statistical Yearbook and the Chinese Environmental Statistical Yearbook. Thus, this study uses Chinese provincial data from 1996 to 2000 for our empirical analysis. Most of the previous EKC studies focus on using cross-country panel data to estimate the relationship between per capita income and various pollution indicators. In this study we move from a cross-country study to an individual country's cross-region study. 
Two water pollutants (industrial water pollution emissions and chemical oxygen demand [COD] in industrial water pollution), three air pollutants (industrial dust emissions, industrial smoke emissions, and sulphur dioxide emissions) and one solid pollutant (industrial solid waste) are examined here. The relative abundance of a pollutant variety makes the income-pollution relationship caused by different pollutants comparable. Moreover, unlike other researchers, we study more pollution indicators and add additional important pollution control policy variables-such as the share of agriculture and manufacturing in the total output, the degree of openness, and government pollution abatement policies-into pollution equations to explain the impact of those variables on China's environmental quality change.

\section{Model specification and data description}

Based on the discussions in the previous section, we specify the simultaneous two-equation model of income and the environment as follows to estimate the relationship between pollution emissions and per capita income in China

$$
\left\{\begin{array}{l}
P_{i t}=c_{i}+\gamma_{1} Y_{i t}+\gamma_{2} Y_{i t}{ }^{2}+\gamma_{3} X_{i t}+\mu_{i t} \\
Y_{i t}=\alpha_{i}+\beta_{1} P_{i t}+\beta_{2} K_{i t}+\beta_{3} H_{i t}+\beta_{4} L_{i t}+\varepsilon_{i t}
\end{array}\right.
$$

Equation 1 represents the pollution equation, where $P_{i t}$ denotes pollutant emission in province $i$ for year $t, Y_{i t}$ denotes per capita income in province $i$ for year $t, c_{i}$ is the specific effect on province $i$; and $\mu_{i t}$ is a normally distributed error term. Here, income $\left(Y_{i t}\right)$ functions as a surrogate variable representing the aggregate effects of those direct and indirect driving forces on pollution. Of particular importance are the signs and magnitudes of $g_{1}$ and $g_{2}$ in Equation 1. Pollution emissions can be said to exhibit an inverted-U EKC relationship with per capita income if $g_{1}$ is greater than zero and $g_{2}$ is less than zero, and if the turning point, $-g_{1} / 2 g_{2}$, is a 'reasonably' low number. In addition to the income terms, we add other important variables into the pollution equation, such as trade, industrial structure, technological progress and environmental policy, to investigate the impact of various exogenous variables on the EKC relationship. Here, $X_{i t}$ represents this kind of control variable.

Equation 2 is an extended Cobb-Douglas production function. In this specification, output is a function of pollution emissions $\left(P_{i t}\right)$, physical capital $\left(K_{i t}\right)$, raw labour $\left(L_{i t}\right)$ and human capital $\left(H_{i t}\right)$. Here, $a_{i}$ is the specific effect on province $i$; and $e_{i t}$ is a normally distributed error term. It is expected that all but the pollution variable should contribute positively to output growth. Here too, pollution $\left(P_{i t}\right)$ functions as a surrogate variable representing the aggregate effects of those direct and indirect driving forces on production. 


\section{Data description}

We study the interactions between pollution emissions and per capita income using China's provincial data during 1996-2000. The form of panel data used provides us with a larger number of sample data than only time-series or crosssectional data sets. We chose the sample period from 1996 to 2000 because average educational attainments in each province were available only since 1996. Thirty provinces are included in our sample, excluding Tibet, since the time-series data of some key indicators in Tibet Province were unavailable.

Pollution indicators are chosen in this study as follows: two water pollutants (industrial water pollution emissions and COD in industrial water pollution), three air pollutants (industrial dust emissions, industrial smoke emissions and sulphur dioxide emissions) and one solid pollutant (industrial solid waste), from 1996 to 2000 in 30 of China's provinces and metropolitan cities. Table 15.1 lists the description of all the pollutant variables and our data sources.

Income per capita is used as the independent variable instead of the total national income, since changes in income per capita can better capture the real impact of income levels on environmental quality. In this chapter, income per capita is measured as GDP per capita, which has been deflated, with 1996 as the base year price. The data sources of GDP per capita are the various issues of the Chinese Statistical Yearbook.

There are a number of pollution control variables. The first are government environmental regulation policies. It has been generally acknowledged that environmental regulation and monitoring by governments plays an important role in environmental pollution control. The cumulative number of environmental standards issued by local governments in each province (symbolised as nums) is used to measure the impact of environmental policies on pollution emissions, including water pollution and air pollution standards. The data sources are various issues of the Chinese Environmental Statistical Yearbook. The second variable is the regional degree of openness. Based on the theory of comparative advantage, international trade affects environmental quality differently in different countries since pollution-intensive industries generally shift from industrial countries to developing ones, or from those countries which conduct stronger environmental regulation to those whose environmental regulation is much weaker (Copeland and Taylor 1995). Therefore, the inverted-U shape of the EKC identifies the different international specialisation patterns among different countries. Industrial countries generally specialise in those industries with less pollution emissions, while developing countries specialise in resource-intensive or energy-intensive products 
Table 15.1 Six indicators of environmental pollution

Pollutant

Industrial water pollution emissions

Chemical oxygen demand in industrial water pollution Industrial dust emissions Industrial smoke emissions

Sulphur dioxide emissions Industrial solid waste
Unit

100 billion kilograms

10 million kilograms

10 million kilograms

10 million kilograms

10 million kilograms

10 million kilograms
Sign

indwater

indcod

inddust

indsmoke

$\mathrm{SO}_{2}$

indsolid

Sources: Various issues of Chinese Statistical Yearbook and Chinese Environmental Statistical Yearbook during 1996-2000.

(Cole et al. 2000), which is usually concluded as the Pollution Haven Hypothesis. The degree of openness (open), which is the ratio of total trade volume to GDP in each province, is used to measure the effects of international trade on environmental pollution, and the data sources are the various issues of the Chinese Statistical Yearbook. The third variable is the technology progress effect, which means that with the enhancement of income levels and economic development, it is possible to spend more on research and development of cleaner technology and more environmental abatement technologies might be adopted; therefore, environmentally friendly technological progress and research and development expenditure might directly help to decrease pollution emissions. We use environment-related research and development expenditure to measure such technology effects, which are symbolised as envrd, and the data sources are various issues of the Chinese Environmental Statistical Yearbook. Finally, we also consider the effect of industrial structural change on pollution emissions since there is a close relationship between the two. In the initial take-off stage of industrialisation, rapid economic development usually occurs, with an increasing share of manufacturing among the total national output, leading to the excessive depletion of natural resources and the rapid increase of industrial pollution emissions (Dasgupta et al. 2002). With the adjustment and update of economic growth patterns and industrial structures, the share of manufacturing in the total output will remain constant or even decline, while the share of tertiary industries will rise. Therefore, since economic development depends less on energy and natural resource inputs, and technological advances and productivity improvement play key roles in economic growth, environmental protection pressures will be alleviated due to such changes in growth patterns. To capture the impact of industrial structural change on pollution emissions, we use the share of agriculture and 
manufacturing in the total output, symbolised as shagri and shaind respectively. The data sources are various issues of the Chinese Statistical Yearbook.

The effects of the following factor inputs as well as environmental pollutants on provincial economic growth are also investigated in our output equation. The first is physical capital stock $\left(K_{i t}\right)$, and we cite the estimation data of Zhang et al. (2004) on China's provincial physical capital stock from 1952 to 2000 to measure the effect of physical capital stock change on provincial economic growth. The role of human capital investment is also considered. As usual (Barro and Lee 2000), the average educational attainment is used to measure the growth effect of human capital accumulation, which is the ratio of total educational attainment to the total population. Following Wang (2000), the education attainment is specified as six years for primary school graduates, and nine, 12 and 16 years for junior middle school graduates, senior middle school graduates and university graduates respectively. Finally, we also consider the effects of labour inputs $\left(L_{i t}\right)$ on provincial economic growth, which are measured as the total employment in each province, and the data sources are various issues of the Chinese Statistical Yearbook.

\section{Empirical estimation and results analysis}

For our estimation method consideration, we chose a feasible GLS specification (FGLS) to consider the presence of cross-section heteroskedasticity, that is, crosssection weights are used to correct for the cross-section heteroskedasticity. First, we perform preliminary estimations to obtain cross-section specific residual vectors, and then we use these to form estimates of the cross-specific variances. The estimates of the variances are then used in a weighted least squares procedure to form the FGLS estimates. A two-stage least squares estimation method is also used since the output and pollution equations are estimated simultaneously. Meanwhile, considering the significant regional disparity between economic development and other economic indicators, cross-section specific effects are also included in our estimations to capture the specific regional disparity.

Simultaneous estimation results for six pollution indicators

Estimation results of the simultaneity model of economic growth and environmental quality changes are provided in Tables 15.2 and 15.3 respectively, with the upper set of regressions being the pollution equations. As shown in Tables 15.2 and 15.3 , in the pollution equations various pollutants are functions of GDP per capita as well as a series of pollution control variables, including the degree of openness and changes in industrial structure. The lower set of regressions is the output equation, among which we regress output levels on three commonly used 
production factor variables, including physical capital, human capital and labour, as well as flows of pollutants.

\section{Analysis of pollution equations estimations}

As for the estimated results of six pollution indicators, we focus on two issues: whether there is a Kuznets inverted- $U$ curve relationship between China's economic growth and environmental quality change; and, what is the effect of various pollution control variables on the emission of various pollutants?

We first analyse the effects of economic growth on the quality of China's environment. According to our simultaneous estimation results in Tables 15.2 and 15.3, among the six pollution indicators we have chosen, five fit into the inverted-U shape curve, except indcod ${ }_{i t}$, which has a U-shape relationship with economic growth. A further analysis of the turning points of the inverted-U curve demonstrates two interesting findings. Firstly, the turning point of GDP per capita can be calculated as 33,010 yuan per capita (indwater ${ }_{i t}$ ), 34,040 yuan per capita (indsolid ${ }_{i t}$ ), 32,200 yuan per capita (indsmoke $e_{i t}$ ), 32,690 yuan per capita (inddust $t_{i t}$ ) and 32,850 yuan per capita $\left(S_{2 i t}\right)$. It can be concluded that the threshold values of GDP per capita along China's Kuznets inverted-U curve generally are above 30,000 yuan per capita. Interestingly, during our sample period, the real GDP per capita for the 30 provinces was much lower than the threshold values we have estimated here. Comparing the GDP per capita for the top five provinces, (Table 15.4) with the calculated threshold values, we conclude that even though a Kuznets inverted-U curve exists for China's environmental quality and its economic growth, the real provincial GDP per capita hasn't reached the threshold value of the EKC yet. Specifically, the average GDP per capita in 2000 was only 8,490 yuan (1996 as the base year price), nowhere near the estimated turning point of the EKC. Even for Shanghai, which has the highest of our estimated inverted-U curve. Therefore, although our estimated results support China's EKC hypothesis, as far as China's real GDP per capita is concerned, the economy still lies on the left side of the inverted-U curve; that is, a further increase in GDP per capita will lead to an increase in the amount of pollution emissions, and the cost of rapid economic growth will be the degradation of the environment. The simultaneous-equation estimation method considers the feedback on environmental pollution on China's economic growth, identifying a more realistic relationship between economic growth and environmental quality than single-equation estimations. In addition, the turning points of China's EKC that we estimated could not be calculated using single-equation estimations.

We can also compare our estimated turning points for China's EKC with those of other authors. Table 15.5 lists some of them. ${ }^{3}$ Interestingly, compared with 


\section{Table 15.2 Simultaneous estimation results on water pollutants and solid pollutants}

\begin{tabular}{|c|c|c|c|}
\hline \multicolumn{4}{|c|}{ Pollution equation estimation results } \\
\hline & \multicolumn{2}{|c|}{ Water pollutants } & \multirow{2}{*}{$\begin{array}{c}\text { Solid pollutants } \\
\text { indsolid }_{i t} \\
107.87(1.821)^{*}\end{array}$} \\
\hline$Y_{i t}$ & $\begin{array}{c}\text { indwater }_{i t} \\
1.393(1.675)^{*}\end{array}$ & $\begin{array}{c}\text { indcod }_{i t} \\
-4.804(-8.038)^{\cdots * *}\end{array}$ & \\
\hline$Y_{i t}^{2}$ & $-0.211(-1.997)^{* *}$ & $2.292(7.192)^{* * *}$ & $-15.834(2.179)^{*}$ \\
\hline nums $_{i t}$ & $0.021(1.256)$ & $0.142(0.591)$ & $-3.251(-0.635)$ \\
\hline open $_{i t}$ & $-0.122(-1.986)^{* *}$ & $-0.369(-5.570)^{* * *}$ & $-1.901(-1.134)$ \\
\hline envrd $_{i t}$ & $-0.028(-2.382)^{* *}$ & $-0.159(-3.047)^{* * *}$ & $-0.638(-3.053)^{*}$ \\
\hline shagri $_{i t}$ & $0.142(5.933)^{\ldots * *}$ & $-0.209(-2.371)^{* *}$ & $0.861(0.762)$ \\
\hline shaind $_{i t}$ & $0.166(7.211)^{* * *}$ & $0.049(0.347)$ & $2.752(1.985)^{*}$ \\
\hline adjust $-R^{2}$ & 0.578 & 0.395 & 0.441 \\
\hline \multicolumn{4}{|c|}{ Shape of the } \\
\hline \multicolumn{4}{|c|}{ Turning point $(10,000$} \\
\hline yuan per c & 3.301 & 3.229 & 3.404 \\
\hline \multicolumn{4}{|c|}{ Output equation estimation results } \\
\hline & $Y_{i t}$ & $Y_{i t}$ & $Y_{i t}$ \\
\hline indwater $_{i t}$ & $-0.0021(-5.534)^{* * *}$ & n.a. & n.a. \\
\hline indcod $_{i t}$ & n.a. & $-0.0012(-2.583)^{* * *}$ & n.a. \\
\hline indsolid $_{i t}$ & n.a. & n.a. & $-0.0041(-0.153)$ \\
\hline$K_{i t}$ & $0.048(18.037)^{* * *}$ & $0.046(15.471)^{m * *}$ & $0.046(15.104)^{m * *}$ \\
\hline$H_{i t}$ & $0.0936(6.158)^{* * *}$ & $0.0922(5.183)^{\cdots *}$ & $0.0955(5.498)^{* * *}$ \\
\hline$L_{i t}$ & $0.00041(1.513)$ & $-0.00025(-0.125)$ & $-0.00035(-0.176)$ \\
\hline Adjust - $R$ & 0.764 & 0.791 & 0.618 \\
\hline
\end{tabular}

Note: The values in the parentheses are t-statistic of the estimated coefficient, and ${ }^{* *}$, ${ }^{* *}$, * indicate that a coefficient estimate is significantly greater than zero at 1 per cent, 5 per cent or 10 per cent respectively.

other estimations, it can be concluded that China's environmental Kuznets inverted$U$ curve has the turns at much lower levels of GDP per capita. China may surmount its EKC when it is still at a low stage of economic development, since the values of our estimated turning points are obviously lower than those reported in Table 15.5. In Table 15.5, the turning points of GDP per capita generally range from US $\$ 5,000$ to US $\$ 20,000$. For example, List and Gallet (1999) use state-level data in the United States and find that estimated turning points at US\$22,675 GDP per capita. On one hand, such comparisons demonstrate that the EKC hypothesis depends strongly on the pollution indicators, sample data and estimation methods the authors have used. On the other hand, it reminds us that even for developing countries such as China, it is possible that the threshold value of GDP per capita 


\section{Table 15.3 Simultaneous estimation results on air pollutants}

Pollution equation estimation results

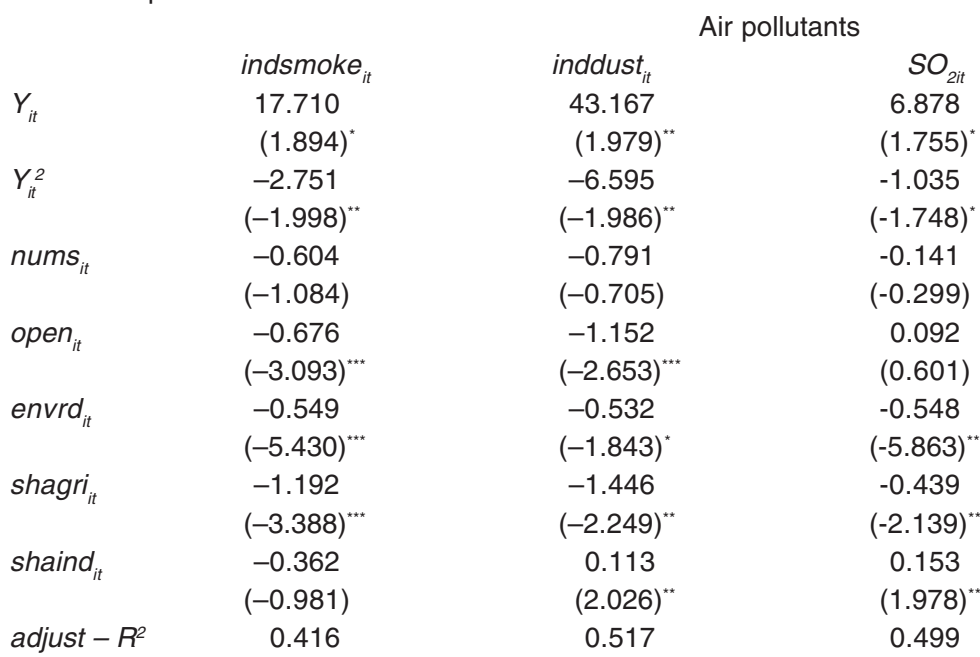

Shape of

the curve Inverted-U curve Inverted-U curve

Turning point

$(10,000$ yuan

per capita)

3.22

3.269

3.285

Output equation estimation results

\begin{tabular}{|c|c|}
\hline indsmoke $_{i t}$ & $\begin{array}{l}Y_{i t} \\
-0.00046 \\
(-0.153)\end{array}$ \\
\hline inddust $_{i t}$ & .. \\
\hline $\mathrm{SO}_{2 i t}$ & n.a. \\
\hline$K_{i t}$ & $\begin{array}{c}0.046 \\
(14.531)^{* * *}\end{array}$ \\
\hline$H_{i t}$ & $\begin{array}{c}0.091 \\
(5.098)^{* * * *}\end{array}$ \\
\hline$L_{i t}$ & $\begin{array}{l}-0.00021 \\
(-0.115)\end{array}$ \\
\hline adjust $-R^{2}$ & 0.713 \\
\hline
\end{tabular}

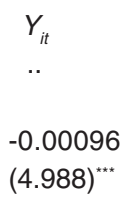

n.a.

0.00019

$(0.473)$

0.045

0.046

$(14.279)^{* * *}$

0.088

$(14.921)^{* * *+}$

0.093

$(4.787)^{*+*+*}$

$(5.351)^{*+*+}$

$-0.00068$

$(-0.314)$

0.694

Note: The values in the parentheses are t-statistic of estimated coefficients, and ${ }^{* *},{ }^{* *}$, * indicate that a coefficient estimate is significantly greater than zero at 1 per cent, 5 per cent or 10 per cent respectively. 
along the EKC can be reached in a relatively low stage of economic development.

Observing the effects of other pollution control variables on pollution emission, we can better understand the reason why China might reach the turning point of its EKC with a lower level of GDP per capita.

First consider the effect of government environmental policies, measured as the cumulative number of environmental regulations issued by local governments. It has been acknowledged that it is necessary for governments to regulate and monitor pollution emissions by individual firms. However, our estimations do not show strong support for the positive role of such government policies. Among the six pollutants we have chosen, the estimated coefficient of nums $_{i t}$ is not statistically significant and the signs of $n_{u m} s_{i t}$ also vary. Two possible explanations for this are provided here. First, whether a government's environmental policies are effective essentially depends on the expectation and response of individual firms, especially those that produce pollution-intensive products. In addition, information asymmetry between governments and individual firms increases the cost of environmental monitoring. What is more, in order to implement stricter environmental regulations, governments usually have to make a decision based on a cost-benefit ratio. It has long been argued that, as with many other government policies, environmental policies, once implemented, usually fail to meet expectations. The second explanation concerns the problem of policy instrumentation when governments attempt to regulate and monitor pollution emissions. It is generally argued that if pollution permission rights can be defined clearly and traded freely in an efficient market, the negative externality of individual pollution activities can be internalised, and direct environmental regulation is not necessary. Therefore, a better outcome might be reached if governments make the effort to promote the establishment of a mature and efficient market for pollution permission rights.

Governments can also regulate environmental quality by increasing expenditure on environmental research and development. The effects of such expenditure have been estimated in Tables 15.2 and 15.3. It can be seen that the estimated

Table 15.4 GDP per capita; the five highest cities in 2000 (10,000 yuan per capita)

\begin{tabular}{|c|c|c|c|c|c|c|}
\hline City (rank) & Shanghai (1) & Beijing (2) & Tianjin (3) & Zhejiang (4) & Jiangsu (5) & Average \\
\hline $\begin{array}{l}\text { Real GDP } \\
\text { per capita }\end{array}$ & 2.799 & 1.847 & 1.686 & 1.329 & 1.174 & 0.849 \\
\hline
\end{tabular}

Note: The real GDP per capita in Table 15.4 are measured with 1996 as the base year price. 
coefficient of envrd it is significantly negative in all six of the pollution equations. While the estimated coefficient of envrd ${ }_{i t}$ in the two pollution equations indwater $r_{i t}$ and inddust $t_{i t}$ is significant ( 5 per cent and 10 per cent respectively), the other four pollutants all show a level of 1 per cent. In addition, the negative sign of the estimated coefficient means that the increase in environmental research and development expenditure helps to abate pollution emissions, which is also the positive technology effect highlighted by Grossman and Krueger (1995). If such a result is compared with the estimated result of nums it it can be concluded that when governments attempt to regulate environmental quality, increasing fiscal expenditure on research and development into clean technology might be more effective than direct environmental regulation.

Economic openness is another important pollution control variable, especially for developing countries such as China. According to the famous pollution haven hypothesis, the effects of international trade on environmental quality differ greatly between industrial and developing countries. If international trade or investment help industrial countries to shift their resource-intensive and even pollution-intensive industries to developing countries, which usually have lower environmental

\section{Table 15.5 Summary of some empirical results on EKC estimations}

\begin{tabular}{|c|c|c|c|}
\hline Author(s) & Sample & Pollution indicator(s) & $\begin{array}{l}\text { Turning point(s) } \\
\text { (GDP per capita) }\end{array}$ \\
\hline \multicolumn{4}{|l|}{ Grossman and } \\
\hline Krueger (1995) & $\begin{array}{l}\text { NAFTA countries, } \\
\text { data source: GAMS }\end{array}$ & $\mathrm{SO}_{2}$, smoke & $4,000-5,000$ \\
\hline \multicolumn{4}{|l|}{ Shafik and } \\
\hline Bandyopadhyay (1992) & $\begin{array}{l}\text { World Development } \\
\text { Report, } 1992\end{array}$ & $\begin{array}{l}\text { Ten indicators including } \\
\text { air and water pollution }\end{array}$ & $3,000-4,000$ \\
\hline Panayotou (1993) & $\begin{array}{l}55 \text { industrial and } \\
\text { developing countries }\end{array}$ & $\mathrm{SO}_{2}$ & 3,137 \\
\hline \multicolumn{4}{|l|}{ Selden and } \\
\hline Song (1994) & Only industrial countries & $\mathrm{SO}_{2}, \mathrm{SPM}, \mathrm{CO}$ & $7,114-13,383$ \\
\hline Panayotou (1997) & $\begin{array}{l}\text { Cities in } 30 \text { industrial } \\
\text { and developing countries }\end{array}$ & $\mathrm{SO}_{2}$ & 5,965 \\
\hline \multicolumn{4}{|l|}{ List and } \\
\hline $\begin{array}{l}\text { Gallet (1999) } \\
\text { Stern and }\end{array}$ & US state-level data & $\mathrm{SO}_{2}$ & 22,675 \\
\hline Common (2001) & $\begin{array}{l}73 \text { industrial and } \\
\text { developing countries }\end{array}$ & $\mathrm{SO}_{2}$ & 101,166 \\
\hline
\end{tabular}

Note: SPM is suspended particulate matter. 
standards, then such international production specialisation patterns will inevitably worsen the problems of environmental degradation in developing countries. Considering China, however, it can be seen from Tables 15.2 and 15.3 that, except that the estimated coefficients of open for the two pollutants $S_{2 i t}$ and indsolid are not statistically significant, the effects of open on the other four pollutants are significantly negative, and their values are -1.152 (inddust), -0.676 (indsmoke), 0.369 (indcod) and -0.122 (indwater). The negative signs of open demonstrate that, unlike in the pollution haven hypothesis, a higher degree of openness helps to abate pollution emissions in China. Two possible explanations are provided here. First, multilateral trade agreements, especially international agreements on environmental regulation, and cooperation indirectly encourage developing countries to update their production technology and adopt cleaner technology. What is more, if developing countries attempt to export to industrial countries, the higher environmental standards imposed on their export commodities usually propel the exporters to adopt more environmentally friendly production technology. Second, technological spillage due to international trade and foreign investment helps to enhance the productivity of local firms in developing countries, and has an indirect effect on the developing country's technological progress and the adjustment of local industrial structures. A large number of studies have confirmed such technology spillage from international trade and foreign investment, ${ }^{4}$ though it is still being debated whether technology absorption depends on the host country's absorptive capability. Empirical studies of China's foreign trade have also justified the important role of international trade in promoting the technological progress of local firms (Lai et al. 2003). Therefore, unlike in the pollution haven hypothesis, international trade might have a positive effect on environmental quality due to this technological spillage. Certainly, since trade volume is the only such indicator used in our estimation, further studies should investigate the effects of trade structure and foreign direct investment on environmental quality in China.

Finally, let us consider the effects of regional industrial structural change on environmental quality. The shares of agricultural (shagri) and manufacturing (shaind) industries are used to measure regional industrial structure. It can be seen from Tables 15.2 and 15.3 that, as far as shagri is concerned, except that the effects of shagri $i_{i t}$ on inwater ${ }_{i t}$ and indsolid ${ }_{i t}$ are significantly positive (0.142) and statistically insignificant, the estimated coefficient of shagri in the other four pollution equations is significantly negative. On the other hand, a significant positive effect of shaind on pollutant emission is estimated. Except for the two pollutants indsolid ${ }_{i t}$ and indsmoke $_{i t}$ it has been found that a larger shaind ${ }_{i t}$ leads to greater emissions of the other four pollutants. 
The general trend of China's regional industrial structural adjustment during our sample years was characterised by the obvious decline of the share of agriculture, while the share of manufacturing remained steady (Table 15.6). Therefore, although China's regional environment is not degraded by the change of manufacturing output, it is degraded by the decrease in the share of agriculture.

If, however, we compare the industrial structure of different regions, those provinces that have a relatively higher share of manufacturing industries are subject to higher pressure for environmental protection. For example, the share of manufacturing industries in Heilongjiang, Zhejiang, Shanxi, Jiangsu as well as Shanghai during 1996-2000 was 54.4 per cent, 53.7 per cent, 51.8 per cent, 51.1 per cent and 50.5 per cent respectively, significantly higher than the national average. Accordingly, those provinces have to make greater efforts to protect their environment from degradation. Generally, as pointed out by many other studies (for example, Dinda 2004), change of industrial structure has been a key variable determining the relationship between economic development and environmental quality, especially the so-called industrialisation process in many developing countries.

\section{Analysis of output equation estimation results}

For output equation estimations, we mainly consider two inputs. The first is fundamental factor inputs, including physical and human capital as well as labour, as emphasised in standard growth theories. The second is the pollutant indicator, which is used to measure feedback from environmental quality change on economic development.

Let us first consider the effects of factor inputs on output change. As the literature on growth theories (neoclassical growth theory and the endogenous growth theory) emphasizes, Tables 15.2 and 15.3 show that physical and human capital accumulation are key variables in determining China's economic growth, which is in line with most theoretical growth models. Among all six output equations, the coefficient of $K_{i t}$ and $H_{i t}$ is significant (1 per cent), especially the $t$-statistic of the estimated coefficient of $K_{i t}$, which has a $p$-value of nearly zero, showing strong evidence that capital accumulation is the key source of China's economic growth. On the other hand, the coefficient of labour inputs, $L_{i t}$, is not statistically significant, and its sign is negative, which doesn't support the role of the raw labour inputs in economic development. ${ }^{5}$

Note here that we use GDP per capita as the dependant variable rather than GDP, and it can be expected that only if labour productivity were obviously enhanced would labour inputs positively affect GDP per capita. 


\section{Table 15.6 Average trends of China's regional industrial structural change, 1996-2000 (per cent)}

\begin{tabular}{llllll}
\hline & 1996 & 1997 & 1998 & 1999 & 2000 \\
The share of agriculture & 22.9 & 21.6 & 20.6 & 19.2 & 17.8 \\
The share of manufacturing & 43.0 & 43.5 & 43.2 & 43.1 & 43.7
\end{tabular}

Source: The authors' calculations, based on relevant issues of the Chinese Statistical Yearbook.

As far as the output effect of pollution emissions is concerned, it can be seen from Tables 15.2 and 15.3 that our estimations can be classified as two types. The effects of indsolid $_{i t}$, indsmoke ${ }_{i t}$ and $\mathrm{SO}_{2 i t}$ on output are estimated to be insignificant, which doesn't support the feedback from environmental quality change on economic growth. In the second type, the pollutants, including indwater ${ }_{i t}$, indcod ${ }_{i t}$ and inddust $t_{i t}$ have a significantly negative effect on $Y_{i t}$ and their estimated coefficients are 0.0021 (indwater $\left.r_{i t}\right),-0.0012\left(\right.$ indcod $\left._{i t}\right)$ and -0.00096 (inddust $t_{i t}$ ), which implies that an increase in those pollutant emissions will cause a decrease in GDP per capita. One of the reasons why environmental pollution negatively affects GDP per capita is that environmental variables affect production via environmental policies that raise production costs and reduce outputs, as emphasised in many theoretical papers such as Selden and Song's (1994). Therefore, improving environmental quality reduces production. On the other hand, the multiple effects of air pollution on production may cancel one another out. For example, improving environmental quality might enhance the productivity of other factor inputs and therefore increase production. When these forces counteract one another, the aggregate effects of air pollutants on GDP per capita are small and the direction might be ambiguous. Additionally, polluters have to pay all of the environmental control and external costs. However, at present in China, external environmental costs of pollution are usually partially internalised because of pressure from economic interest groups and the growth considerations of local governments. For example, the pollution emission fee might not be set sufficiently high to offer enough economic incentives to local firms to adopt cleaner technology and reduce their emissions, especially those polluters that account for a large share of total local output.

\section{Policy implications of the EKC in China}

Combining the simultaneous estimation results of pollution and output equations, we can further investigate the impact of changes of exogenous variables on 
equilibrium pollution emissions and output levels by solving our simultaneity model.

Let us first examine the impacts of pollution control variables. For example, let us investigate how the changes in environmental research and development expenditure will affect pollution emissions and output levels, shown in Figure 15.1. In Figure 15.1, the inverted-U shaped curve is an environmental curve $(E C)$, and the downward line is the output curve $(O C)$, the slope of which is determined by our simultaneous estimation results since the coefficient of pollutants in output equation estimations is negative. The intersection point, $A_{0}$, of the curves $E C_{0}$ and $O C$ at the initial state determines the initial level of equilibrium pollution emission, $P_{0}$, and equilibrium GDP per capita, $Y_{0}$. Let us consider how government expenditure on the research and development of green technology will affect the pollution emissions and GDP per capita, other things being equal. The estimated coefficient of envrd in our pollution equations is negative, implying that an increase in environmental research and development inputs will cause the environmental curve to shift vertically downward to the new curve, $E C_{1}$, while the output curve, $O C$, remains the same, since envrd does not directly affect output levels in the output equations. The new intersection point, $A_{1}$, determines the new level of pollution emissions, $P_{1}$, and GDP per capita, $Y_{1}$, in the new state of equilibrium. Thus, by comparing the initial $P_{0}, Y_{0}$ with the new $P_{1}$ and $Y_{1}$, respectively, we can study how envrd will affect environmental quality and economic development. First, it is easy to see that $P_{1}$ is greater than $P_{0}$, implying that the increase in environmental research and development helps to alleviate environmental pressure due to pollution emissions, the direct environmental effect of envrd. Second, changes in envrd also indirectly affect output levels, since they help decrease pollution emissions. More specifically, $Y_{1}$ is larger than $Y_{0}$, and means that envrd has a positive effect on GDP per capita. This happens because pollution emissions negatively affect output levels, and the decrease in pollutants due to more environmental research and development expenditure will result in a higher GDP per capita, the indirect output effect of envrd. What should be mentioned here is that since the estimated coefficient of pollutants in output equations is relatively small, it means that in Figure 15.1 the slope of the line $O C$ is very steep. Thus, the direct pollution decrease of envrd is much larger than the indirect output increase.

In Figure 15.2, we also investigate the impact of the change of factor inputs on the equilibrium of pollution emissions and GDP per capita. Similarly, it can been seen in Figure 15.2 that the intersection point of $E C$ and $O C$ is the initial equilibrium state, $B_{0}$, and, accordingly, $P_{0}, Y_{o}$ are the initial equilibrium pollution emission and GDP per capita respectively. Let us consider the impact of physical capital accumulation, $K$. 


\section{Figure 15.1 The impact of pollution control variables}

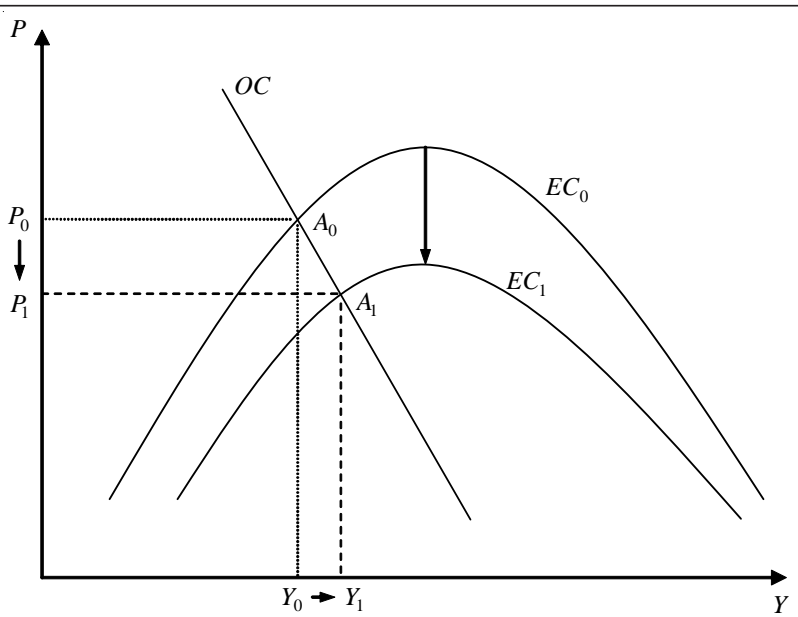

With the increase in physical capital, $K$, the output curve, $O C$, will shift to the right to the new position, $O C_{1}$, since the marginal output effects of physical capital accumulation are estimated to be positive, while the environmental curve, $E C$, remains unchanged. The new intersection point of $O C_{1}$ and $E C, B_{1}$, determines the new equilibrium level of pollution emission $\left(P_{1}\right)$ and GDP per capita $\left(Y_{1}\right)$.

The impact of physical capital accumulation on environmental quality and economic growth are shown in Figure 15.2. On one hand, since physical capital accumulation enhances output level, we have $Y_{1}$ being greater than $Y_{0^{\circ}}$ On the other hand, the increase in GDP per capita will affect pollution emissions. As we have estimated, the turning points of China's regional EKC lie with the GDP per capita being 30,000 yuan (1996 as the base year price), thus generally, at present, China's regional economic development has been the left part of the EKC. What is more, except in a few regions such as Shanghai and Beijing, most of China's provinces are still a long way from the turning points of our estimated EKC. As a result, physical capital accumulation will inevitably exert a negative effect on local environmental quality through the increase in GDP per capita. Thus, it can be concluded that there are both positive direct output effects and negative indirect environmental effects as a result of physical capital accumulation.

Finally, combining the analyses in Figures 15.1 and 15.2, we can see the policy implication of the EKC. Although the EKC might capture the general relationship 
between economic growth and environmental quality change, it might lead us to certain misleading policy suggestions. Since the environmental pressure due to rapid economic growth can be alleviated only after the economy has crossed the turning point along the EKC, it seems that the most effective way to protect the environment is to promote rapid economic growth further until it exceeds the threshold value along the EKC. Such policy implications, however, might be misleading. As estimated in this chapter, for most of China's provinces at present, their real GDP per capita are a long way from the threshold value in the EKC, and means that there is still a long way to go before those provinces reach the turning point of their estimated EKC. Before they get there, environmental degradation will continue to be a consequence of economic growth, since the incomeenvironment relationship remains negative. As is shown in Figure 15.2, only when the economy arrives at the point $B_{2}$, that is, when the GDP per capita is as high as $Y_{2}$, will it be possible to return to the initial environmental quality, $P_{0}$. Also, since environmental abatement costs usually increase with pollution emissions, it is better for governments to regulate and monitor environmental pollution in the economic take-off stage rather than when environmental quality has greatly declined. Additionally, in certain cases, environmental damage cannot be remedied once it has occurred-for example, land erosion, deforestation, irradiation, the loss of species diversity and even the extinction of species. Finally, it should be mentioned that since pollution control variables essentially affect environmental quality, we can simultaneously adjust the levels of environmental pollution and output by combining certain policies. If we combine the analyses of Figures 15.1 and 15.2, for example, a policy combination of increasing environmental research and development expenditure and investment promotion is required. Economic growth can be enhanced by physical capital accumulation and environmental research and development helps to alleviate pressure on the environment due to the negative pollution effect of economic development. In the meantime, the positive output effect of environmental research and development also promotes rapid economic growth, which helps the economy to reach the turning point of EKC more quickly.

\section{Conclusions}

By using the panel data of China's 30 provinces during 1996-2000, this study has made a modest attempt to estimate the interaction between economic development and environmental quality simultaneously. Our empirical results confirm that the hypothesis of simultaneity exists in some pollutants, and our estimations and 


\section{Figure 15.2 The impact of factor inputs}

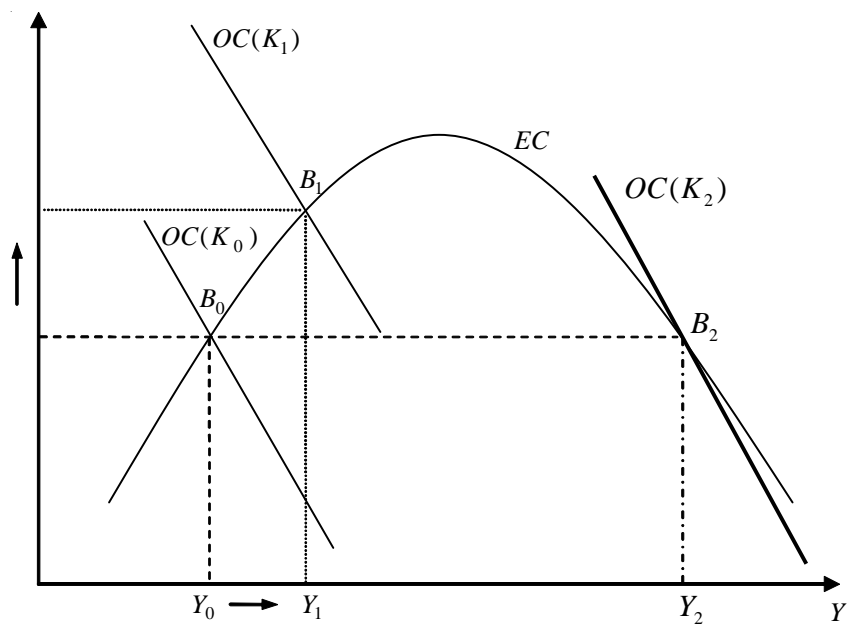

policy implications are explicitly different from those based on single pollution equation estimations.

First, among the six pollution indicators we have chosen, while indcod ${ }_{i t}$ has a Ushaped relationship between economic developments, the five other indicators show an inverted-U curve relationship with changes of GDP per capita. The further estimation demonstrates that the threshold value of GDP per capita along our estimated EKC is generally above 30,000 yuan. It reveals that although the EKC relationship for China has been estimated here, at present China's economic development has been on the left side of the inverted-U curve, implying a negative relationship between economic growth and environmental quality change. In addition, comparing the EKC's threshold value with real GDP per capita of China's 30 provinces, it is easy to see that for most provinces, real GDP per capita is a long way from the threshold values. This means that substantial environmental costs have to be paid before they reach the turning point along their EKC. As emphasised previously, however, promoting economic growth is not the only way to adjust environmental quality, and more attention should be paid to the role of pollution control variables such as environmental research and development, government regulation, industrial structural change and economic openness. Our estimations strongly support the role of these variables in environmental quality change. Specifically, increases in environmental research and development expenditure, as well as improved economic 
openness, help to abate pollution emissions. The role of activist government environmental policy, however, which is measured as the number of environmental regulations, is estimated to be statistically insignificant.

The results of our output equations also support feedback on the effects of environmental quality on economic growth. While three pollution indicators are found to have significantly negative effects on economic growth, the effects of the other three indicators are estimated to be insignificant. It is estimated that the accumulation of physical and human capital investment are key driving forces of economic growth, while the effect of labour inputs on GDP per capita change is insignificant.

Combining our simultaneous estimations of the pollution and output equations, it can be concluded that even though the EKC reflects the relationship between economic growth and environmental quality change in most countries, the view that promoting economic growth is the best way to protect the environment might be misleading. As shown in our analysis, accelerating economic growth by capital accumulation in order to reach the estimated turning point along the EKC is not the optimal policy. It has been estimated that the use of cleaner, environmentally friendly technology, the adjustment of industrial structures and economic openness all play important roles in alleviating the pressure of rapid economic growth on the environment. Therefore, developing countries such as China would be best served by a policy combination of acceleration of economic development and enhancement of environmental abatement capability.

\section{Notes}

1 The first set of empirical EKC studies appeared independently in three working papers: an NBER working paper as part of a study of the environmental impacts of NAFTA (Grossman and Krueger 1991), the World Bank's 1992 World Development Report (Shafik and Bandyopadhyay 1992) and a Development Discussion Paper as part of a study for the International Labor Organization (Panayotou 1993). Grossman and Krueger (1991), in an NBER working paper, which was published in 1993 (Grossman and Krueger, 1993), first pointed out an inverted-U relationship between pollutants (sulphur dioxide SO2 and smoke) and income per capita. Kuznets' name was attached to the inverted-U relationship between pollution and economic development later due to its resemblance to Kuznets' inverted-U relationship between income inequality and economic development. However, Panayotou (1993) first coined it as the Environmental Kuznets Curve or EKC.

2 Pearson (1994), Stern et al. (1996), Arrow et al. (1995), Stern (1998), Ekins (2000) and de Bruyn (2000) provide a series of critiques of the EKC studies.

3 For the literature review on empirical EKC research, see, for example, Stern (1998), Ekins (1997), de Bruyn and Heintz (1998), Stagl (1999) and Dinda (2004).

4 See Keller (2004) for a review of international technological spillage.

$5 \mathrm{It}$ is generally acknowledged that as the economy is transforming to a more service and technology oriented one, the role of human capital will become more important in production, while raw labour becomes correspondingly less important. 